\title{
'Pataphysics and Computing
}

Professor Andrew Hugill

Bath Spa University

UK 

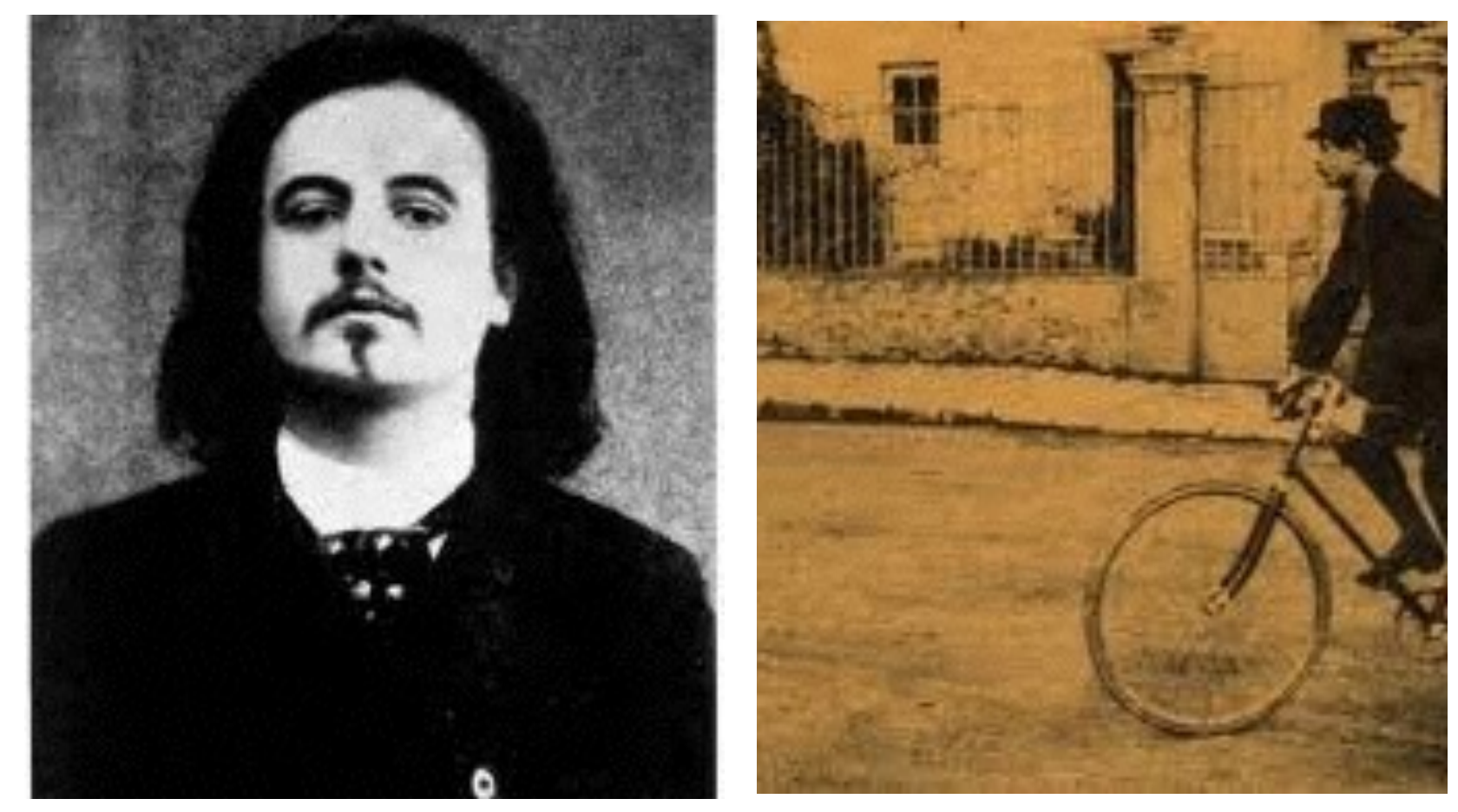

Part of Jarry's genius lay in his awareness that pataphysics was beyond him. Franz Liszt professed to the Princess Carolyne von Sayn-Wittgenstein that he had 'hurled his lance into the future' (Taylor 1986, 262). In Jarry's case, we had better say he fired his pistol into the future, not caring whether the bullet hit its target or swerved into the neighbour's children.

We know this because pataphysics today is a living, breathing, thing. The evidence for its continued vitality is all around us, not only in the work of Collège de 'Pataphysique and its many offshoots and imitators, but also in the multitude of knowing and unknowing indebtednesses revealed in literature and film, music and the visual arts, even the sciences and the social sciences.

Even the sciences? We may suppose that there is an irreconcilable opposition between the subjective truths of pataphysics and the objective truths of conventional science. Yet the reality is more nuanced than that: the relationship between pataphysics and the thing it apparently parodies is never straightforward. Pataphysics today opens up scientific possibilities that Jarry could not have foreseen. These often play themselves out in the zone between the scientific disciplines and what may be called the humanities; although a parenthetical objection may be raised at this point.

Why are Faculties of Life Sciences populated by people in white lab coats, or psychologists behind two-way mirrors, or neuroscientists, or human tissue analysts? Does not literature, or music, or art, or history, have as much to teach us about life as such conventional science? The argument will be made, often by humanities scholars, that these are not scientific disciplines. Their methodologies are different and consequently a distinction must be made. Nothing is more destructive of an understanding of the 'human' aspects of life, advocates of the historical method might argue, than empiricism. The need for pataphysics has never been greater. 


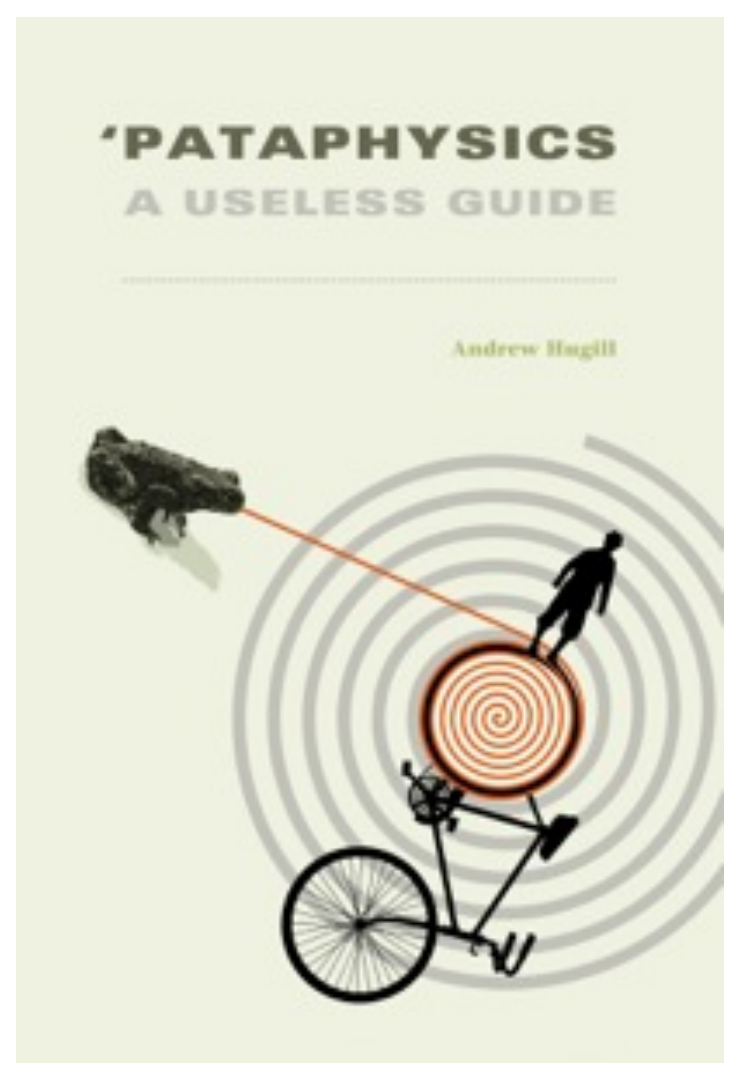

Critical reactions to 'Pataphysics: A Useless Guide emanated from all the orifices of this organism, with the Collège de 'Pataphysique offering the most sober appreciation and Brian Reffin Smith, writing in Leonardo, the most pataphysical one (although a recent review in Bomb by Daniel Levin Becker is a close contender for that appellation).

From the mass of generally positive reviews, two critical positions seemed to emerge. On the one hand, there were those who spotted supposed omissions: artists, works, groups, who should (in the reviewer's opinion) have been included: people who could have been name-checked because they had been working in pataphysics all their lives, right through to figures whose work seems to have had pataphysical overtones and so deserved a mention.

By contrast, and with the telescope firmly round the other way, a couple of negative reviews (which emanated, it has to be said, entirely from one particular location in London) took the book to task for precisely the opposite reason: that it included people whose connection with pataphysics and Jarry was apparently either questionable or non-existent, and that it consequently failed to deliver a "pataphysics proper". Yes indeed. 


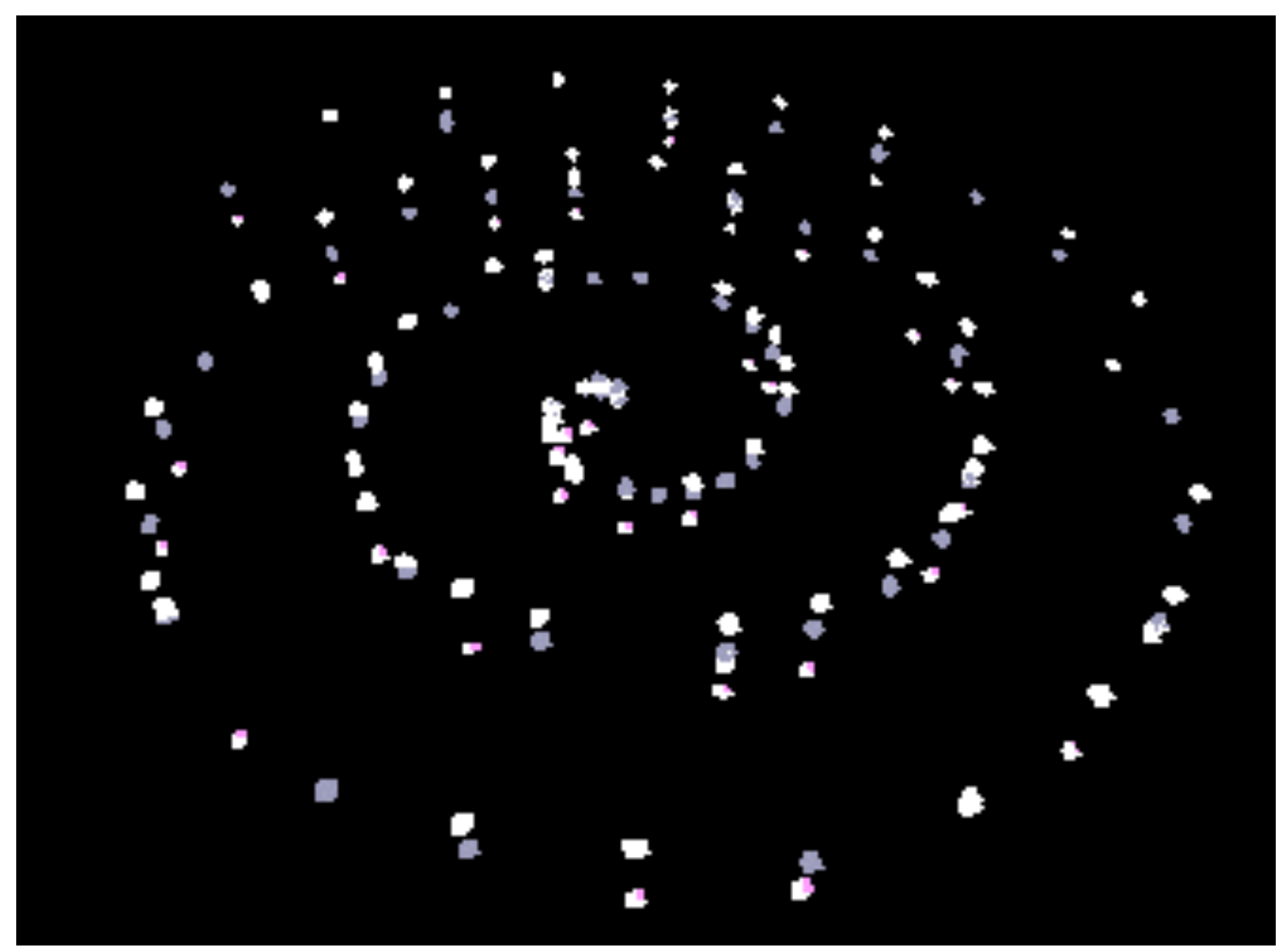

This pata-physician now seeks to observe further the inhalations and exhalations of the organism, by examining a topic of which Jarry could not possibly have been aware: computing.

To link the two may, at first glance, seem rather contrary. Even so, this is not the first such attempt: Johanna Drucker and her colleagues at the University of Viriginia's SpecLab set out an integrated approach to pataphysics and computing within the context of the digital humanities from 2000 onwards. No less significant are the ways in which various pataphysical artists have used computers either as a metaphor or a tool in their creative practice. There is also a historical dimension, connected to the impact of the evolution of computer technology on postwar artistic and cultural developments, including the OuLiPo.

The paper will introduce some original research, particularly in the field of semantic web and search technologies, which tries to apply pataphysics within a domain that at first glance may appear utterly unsympathetic. This extremophilic experiment is designed to test the veracity of the statement that pataphysics is still alive. We will see if that proves to be the case. But first, in order to understand how pataphysical thinking may connect with computer science, we must examine Jarry's approach to technology in general and mathematics in particular. 


\section{Mollet: The Unknown Jarry}

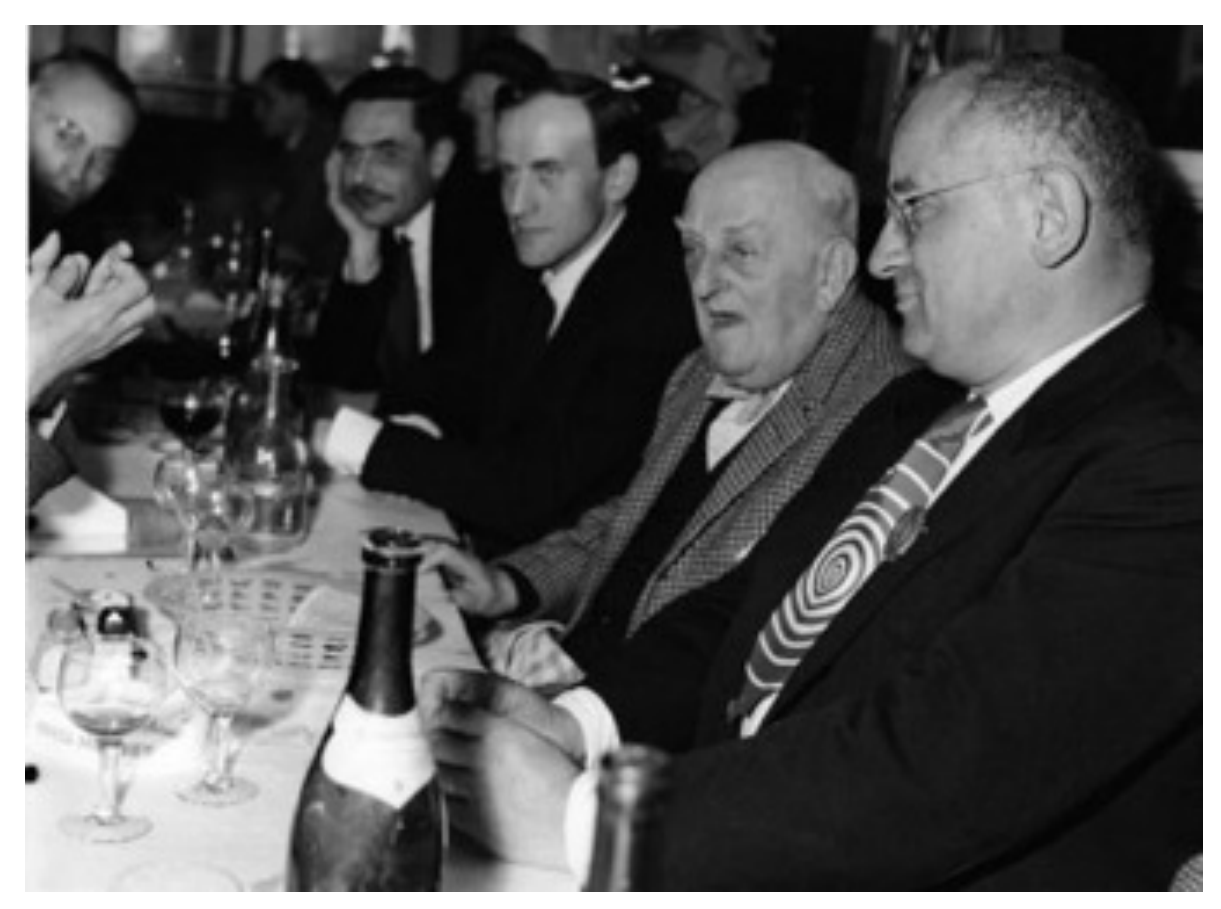

In his brief text "Jarry inconnu" (The Unknown Jarry, 1962), Baron Mollet set out to debunk the myth that Jarry was nothing more than an eccentric poet:

"His predilection was chiefly for mathematics, in which he was excessively gifted. Indeed, he kept up a long correspondence with foremost mathematicians. I remember one day when I was to fetch him for lunch, I found him barefoot, in his underpants, shirtless, his eternal bowler hat upon his head, tracing numbers with a piece of chalk on the wall of his flat. As I was hurrying him along, for we were late, he said: "What! I'm ready and I was waiting to you; look, I have my hat on." (Brotchie 1995, 92). 


\section{Lord Kelvin/Irénée Sandomir}
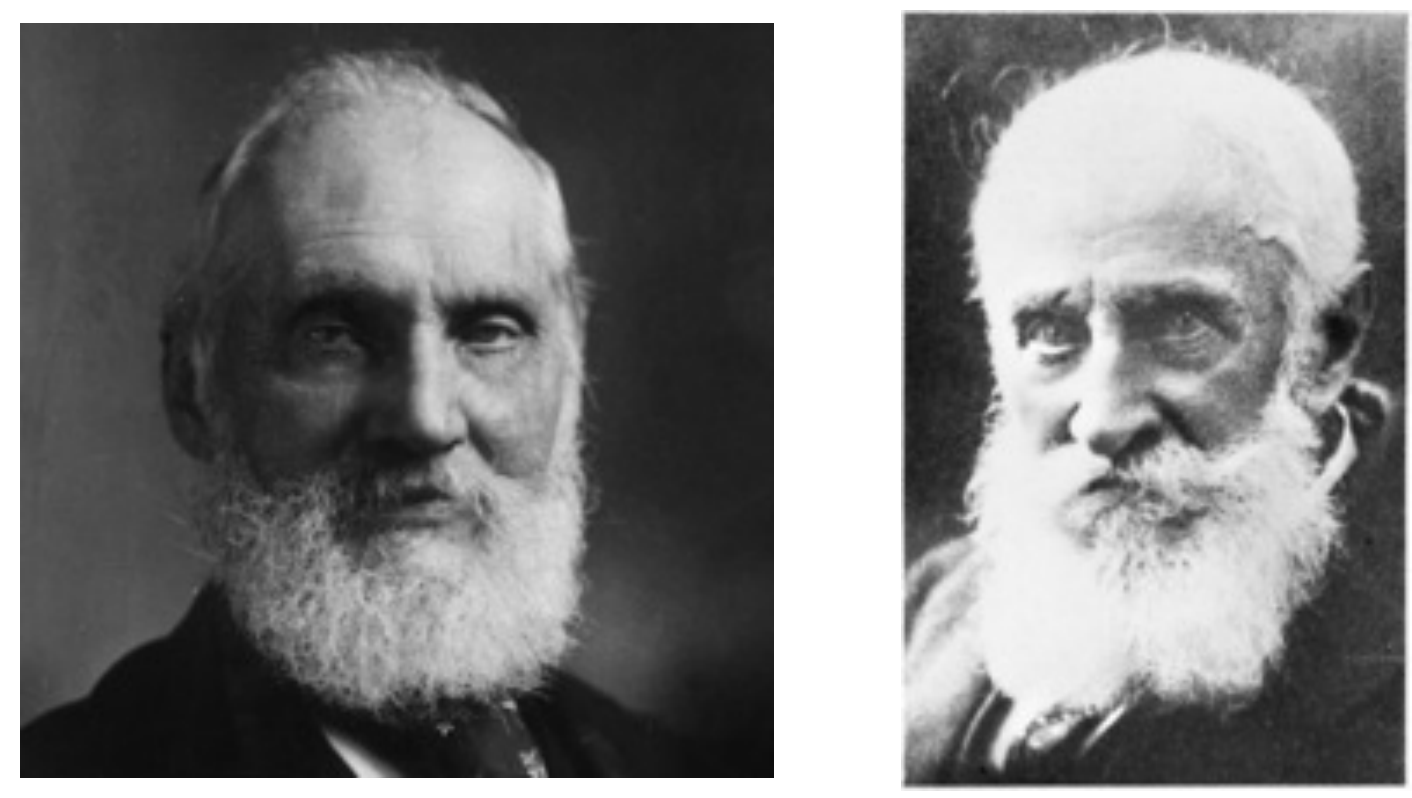

Jarry's writings show that his approach to mathematics was in every respect equivalent to his approach to all the other orthodoxies of his time, in other words it was pataphysical. It is best summarised in the celebrated telepathic letter from Dr Faustroll to Lord Kelvin, who wrote in Volume 1 of his Popular Lectures and Addresses (1893):

I often say that when you can measure what you are speaking about, and express it in numbers, you know something about it; but when you cannot measure it, when you cannot express it in numbers, your knowledge is of a meagre and unsatisfactory kind; it may be the beginning of knowledge, but you have scarcely in your thoughts advanced to the state of Science, whatever the matter may be. (Thomson 1889 [1883], 73-74)

To which Doctor Faustroll replies:

We are both of the opinion that, if one can measure what one is talking about and express it in numbers, which constitute the sole reality, then one has some knowledge of one's subject. Now, up to the present moment I know myself to be elsewhere than on earth, in the same way that I know that quartz is situated elsewhere, in the realm of hardness, and less honourably so than the ruby; the ruby elsewhere than the diamond; the diamond than the posterior callosities of Bosse-de-Nage. [...] But was I elsewhere in terms of date or of position, before or to the side, after or nearer? I was in that place where one finds oneself after having left time and space: the infinite eternal, Sir. (Jarry 1965 [1911], 246-247) 


\section{Cesar-Antichrist}

The Pataphysician, axiom and principle of the identity of opposites, clamped on to your your ears, and you, flyingfish, to your retractable wings, is the dwarf atop the giant, beyond metaphysics; he is, through you, the Antichrist and God as well, horse of the Spirit, Minus-in-Plus, Less-whichis-More, kinematics of the zero left in our eyes, polyhedral infinity (Jarry 2001, 142).

Jarry's use of algebra goes back as far as Cesar-Antichrist, in which the plus-minus becomes the physick-stick, the uprooted phallus of Lautréamont that "leaps about so". The minus sign spins across the imagined stage, its rotations turning it into a plus sign, prompting this speech of the Fess.

For the Symbolist Jarry, it was mathematical symbols that offered the strongest poetic and philosophical possibilities, since they represent not just abstractions but truths, whose limits and fixity may be challenged and tested. Like the constraints governing his physical existence, they are fodder for his anarchic imagination. They become interchangeable with letters: atomic units of potential meaning that may be turned and deflected by a clinamen or a syzygy. Just as the ' $r$ ' in merdre deviates the meaning of the word, so the infinity sign in Faustroll changes the meaning of the math. It is not so much that the mathematical symbols acquire a life of their own, as in Edwin Abbott's Flatland, but rather that the logic of the maths itself is subject to pataphysical operations, to playful (and not so playful) distortions.

For Jarry, then, numbers represented liberation: liberation from words and their imprecisions. He was not alone in this. As Matthieu Gosztola points out, Paul Valéry, whom Jarry described as "our copataphysician and illustrious chronicler of the fourth Tetrahedron" in a dedication in Ubu enchaîné, was an enthusiastic proponent of what he called "la liberté mathématique" (Valéry 1958, 194). 


\section{Archaeopteryx}

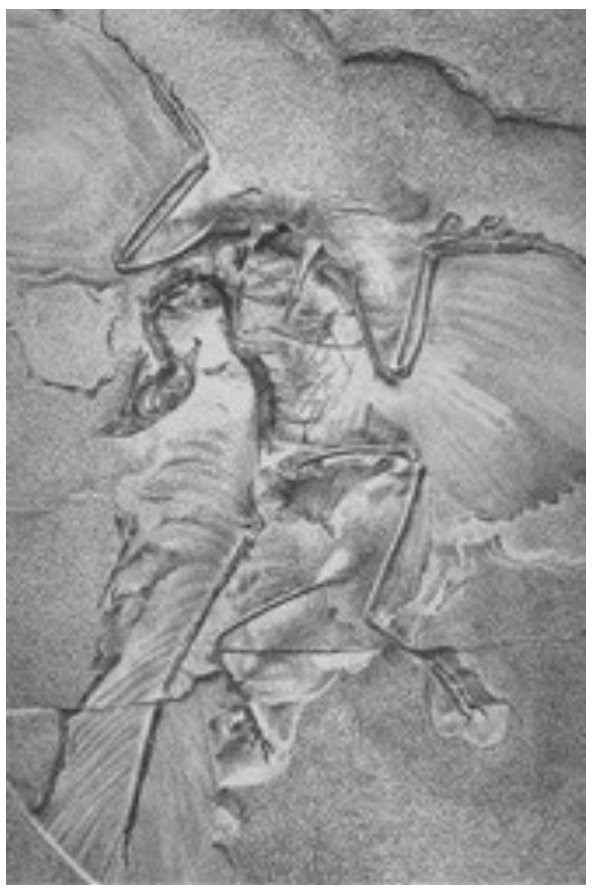

Mère Ubu : Ah! mon Dieu, que tenez-

vous là? C'est lui, le bel oiseau, le coco!

Je le reconnais. II a bien toujours (mais il

grandira!) - $0 \mathrm{~m} 25$ de long, $0 \mathrm{~m} 30$ avec

les pattes allongées, $0 \mathrm{~m} 05 \mathrm{de}$

diamètre, $0 \mathrm{~m} 25$ d'envergure, $0 \mathrm{~m} 08$

d'oneilles, 0 m 04 de queue. (Ubu Cocu

Act I Sc 8).

Photo of Archaeopteryx, 1881

Linda Klieger Stillman points out that Jarry was writing at a time when the machine was increasingly present. The true representative hero of the era was "neither the genius nor the saint nor the king nor even the superman, but a robot" (Stillman 1985, 107).

Whereas H. G. Wells conceived a Time Machine, but was rather imprecise about its construction, Jarry's Time Machine is described in mathematical detail and consequently succeeds in being a much more effective vehicle for imaginary solutions. Wells, of course, stood in a long line of social commentators who used time travel as a convenient plot device for their speculations. For Jarry, on the other hand, the time machine is evidence of pataphysics, and hence the power of meta-irony.

Sometimes, Jarry uses numbers simply to make us laugh, such as in the opéra bouffe Le Moutardier du pape, where we find the following witticism:

Statistically speaking, Madame: if 999 out of every one thousand foreigners is English, there are a thousand over 999 chances that one of these English could be your husband. (Aside). I think I'm wrong there, but that'll impress her.

This kind of joke becomes more obviously pataphysical in the Ubu plays. In Ubu Cocu, for example, Ma Ubu exclaims, upon seeing her child the archaeopteryx: 


\section{Dr. Faustroll}

Le docteur Faustroll naquit en Circassie, en 1898 (le $x x^{e}$ siècle avait (-2) ans), et à l'âge de soixante-trois ans.

A cet âge-là, lequel il conserva toute sa vie, le docteur Faustroll était un homme de taille moyenne, soit, pour être exactement véridique de $\left(8 \times 10^{10}+10^{9}+4 \times 10^{8}+5 \times 10^{6}\right)$ diamètres d'atomes; (Faustroll Book I Chapter II, pp. 4-5)

This anticipates the celebrated description of Faustroll.

This didactic mode is typical of Jarry's mathematically-influenced writings. The archaeopteryx is described by Mère Ubu as if reading from a museum catalogue, whereas the imaginary individual Dr Faustroll is described as if from a physics textbook. Both descriptions are reminiscent of Jarry's remark to Rachilde that she, like himself, is "a negligible assembly of atoms". Here, the pataphysical refinement is an extreme atomic precision. With such detail, the clinamen may come into operation at the corporeal level and the body may become a pataphysical entity. 


\section{Cowlick}

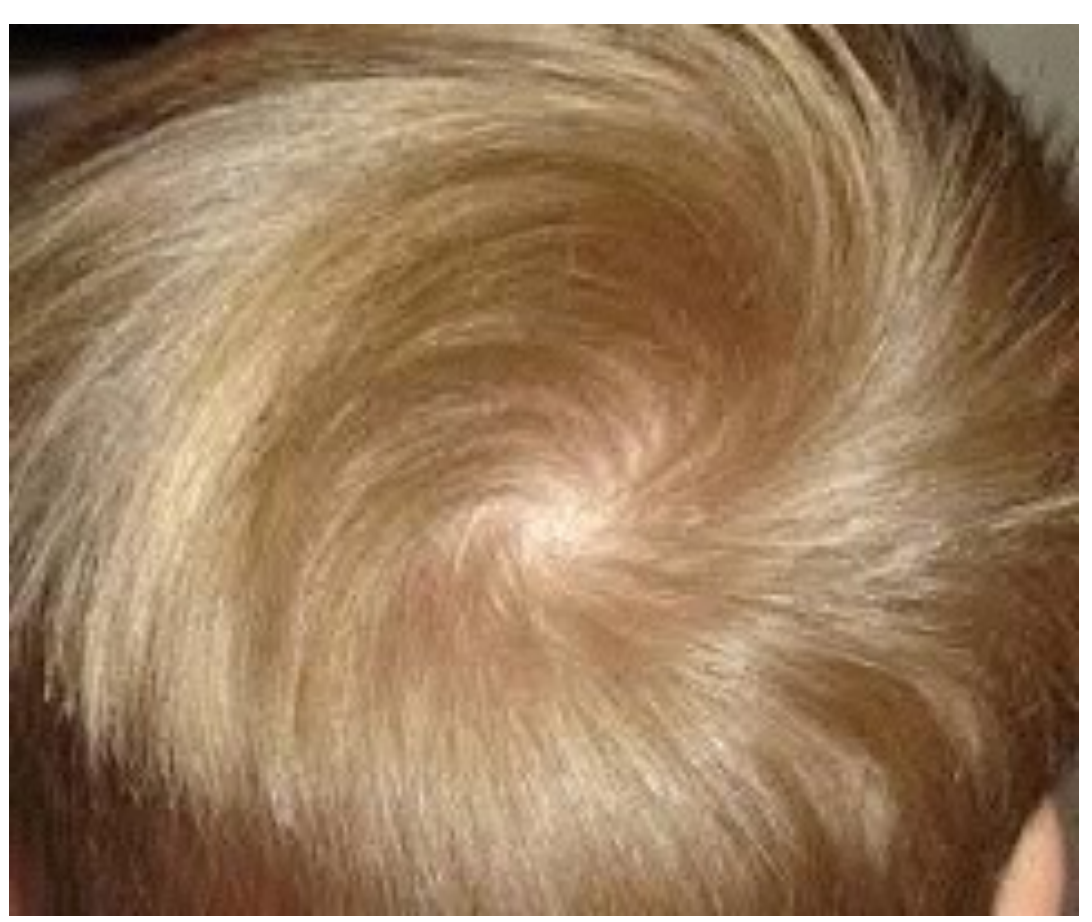

Geometry is just as important as arithmetic in Jarry's writings. The pedantic precisions of Achras' polyhedra contrast with the misshapen blob that is Ubu, who is the very embodiment of the 'hairy ball' theorem of mathematician Henri Poincaré. This states (in its modern version): "you can't comb a hairy ball without creating a cowlick". A cowlick is the spiral of hair that arises when you try.

The pataphysical version of this algebraic topology might say: you can't decorate Ubu's belly without creating a cornegidouille. 


\section{Faustroll}

The first postulate concerns the trinity expressed as a triangle:

Therefore, POSTULATE:

Until we are furnished with more ample information and for greater ease in our provisional estimates, let us suppose God to have the shape and symbolic appearance of three equal straight lines of length $a$, emanating from the same point and having between them angles of 120 degrees. From the space enclosed between these lines, or from the triangle obtained by joining the three farthest points of these straight lines, we propose to calculate the surface.

The geometrical precision of the celebrated definition of the surface of God in Faustroll plays a similar game with algebraic symbols in order to furnish a pataphysical proof.

Once again, it is delivered in a didactic mode that exaggerates the precisions of its formulae. Notice, also, that it is a superficial description that concentrates upon surface rather than substance, seeing the resulting surface as evidential of the substance beneath. God therefore occupies a threedimensional space of indeterminate dimension emanating from a single point, and the resulting surface is triangular. 
Let $x$ be the median extension of one of the Persons $a, 2 y$ the side of the triangle to which it is perpendicular, $N$ and $P$ the extensions of the straight line $(a+x)$ in both directions $a d$ infinitum.

Thus we have:

$x=\infty-N-a-P$.

But

$N=\infty-0$

and

$P=0$.

Therefore

$x=\infty-(\infty-0)-a-0=\infty-\infty+0-a-0 x=-a$.

We may observe at this point that the mathematics has already passed beyond metaphysics into pataphysics. Taking nothing away from infinity only gives us metaphysics. But when one contemplates the symbolic game of this imaginary solution of an equation as a whole, one realises that the entire thing may be seen another way. 
As the watch on its side is an ellipse, so the equation may be viewed as a totem-pole, or rather a physick-stick, made from a series of impossible relationships between imaginary solutions. [HIT RETURN TO ROTATE THE EQUATION!] 


\section{JOOTSY Calculus}

- $2+2=(9-8)(9-8)$ [Inversion]

- 2 teacups plus 2 teacups $=40$ cups [T-Math]

- one plus twelve $=1+12$ [Honest]

- seven plus seven $=7+7$ [Honest]

This kind of mathematics was developed in various ways. Time prevents us looking at Boris Vian's mathematics of Dieu and René Daumal's games on the same topic.

More recently, JOOTSY Calculus, a branch of metamathematics in which calculations are not limited to just one alphanumeric system but allowed to JOOTS, "Jump Out Of The System" in which it began or had been previously "jootsed". The name derives from the Chinese philosopher and that protopataphysicist, Dzu-tse (also known by the Latinized Jucius and the Anglicized Jootsy).

In this system, one can use any mathematical representation included in the set of Generalized Orthographic Denotations, or GOD. So, for example, to solve $2+2=$, there are many possible answers (other than 4), such as the inversion (read upside down)

$(9-8)(9-8)$

or the T-Math

2 teacups plus 2 teacups $=40$ cups.

"Honest calculations" have the same number of letters as the meaning of the expression, so: one plus twelve $=1+12$, or seven plus seven $=7+7$. And so on, for hundreds of examples. 
We can say that $a$ is a straight line connecting 0 and $\infty$, and can define God thus:

DEFINITION: God is the shortest distance between zero and infinity.

In which direction? one may ask.

We shall reply that His first name is not Jack, but Plus-and-Minus. And one should

say:

\pm God is the shortest distance between 0 and $\infty$, in either direction.

Which conforms to the belief in the two principles; but it is more correct to

attribute the sign + to that of the subject's faith.

But God being without dimension is not a line. - Let us note, in fact, that,

according to the formula

$\infty-0-a+a+0=\infty$

the length $a$ is nil, so that $a$ is not a line but a point.

Therefore, definitively:

GOD IS THE TANGENTIAL POINT BETWEEN ZERO AND INFINITY. Pataphysics

is the science...

Jarry's chapter concludes of course with this celebrated formulation.

The insubstantiality, one might even say virtuality, is typical. The materials of pataphysics in the world, all the machines and museums, all the books and works of art, are merely evidence of pataphysics itself. Just as Faustroll agreed with Kelvin that number is the root of everything, so we can only know the existence of pataphysics because it "symbolically attributes the properties of objects, described by their virtuality, to their lineaments". As Ruy Launoir observed:

We must, by considering the possible ways in which we can imaginatively extend all the aspects of an object, be able to combine them in order to obtain a new representation of a linear "something"; pataphysical freedom will be attained at the moment when we can think of objects at once as ordinary and in many other ways, being conscious only of the differences in ingenuity between these representations. (Launoir 2005, 22-23) 


\section{OuLiPo}

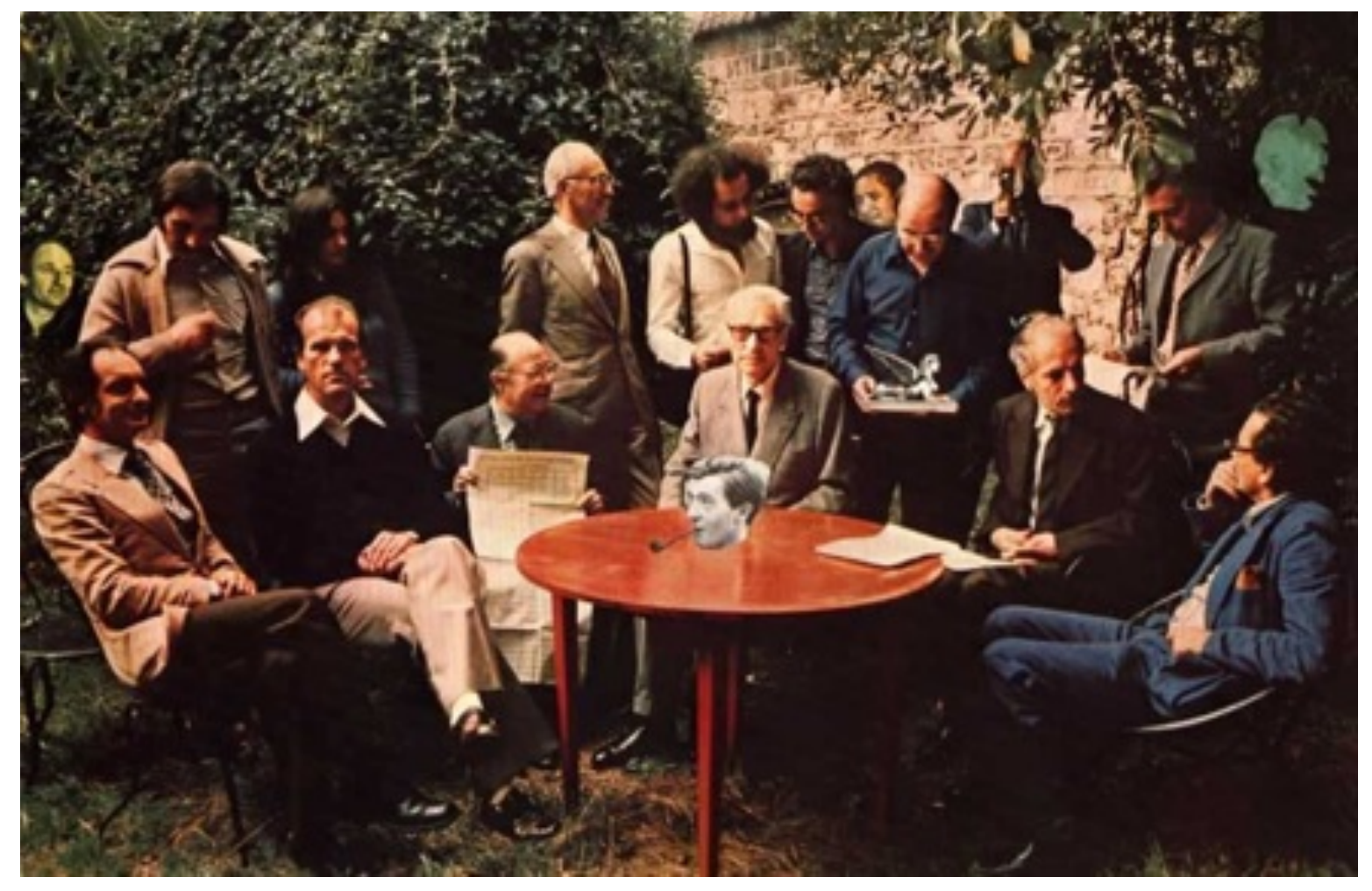

All of which brings us to the OuLiPo, who are perhaps the most self-conscious inheritors of Jarry's mathematics. In general, academic criticism has increasingly tended to appreciate the OuLiPo for its many literary achievements. Indeed, the OuLiPo is usually viewed as a kind of literary movement, whose primary exponents are Queneau, Perec, and Calvino. Yet we should bear in mind that the OuLiPo itself exists to make potential rather than actual literature, and that it does so by the creation of rules whose logic frequently resembles computational processes and which occasionally go under the name of "algorithms".

In the early days, there were links between the OuLiPo and 'Nicolas Bourbaki', the collective pseudonym of the group of mathematicians who advanced set theory as a basis for mathematics. Queneau's translation of David Hilbert's Foundations of Geometry replaced the words "points", "lines" and "planes" with "words", "sentences" and "paragraphs". Queneau attended a Bourbaki conference in 1962, and other Oulipians, such as Claude Berge and Jacques Roubaud, also had connections with the group.

Bourbaki influenced structuralism, and it is not hard to see the way in which Oulipian constraints, with their anonymising effects, anticipate the general evolution of critical theory towards the transition point marked by Roland Barthes' essay 'The Death of the Author' in 1968. At any rate, the computer began to be used explicitly by the Oulipo in the early 1970s, mainly through the efforts of Paul Braffort to realise the combinatorial possibilities of the Cent mille milliards de poèmes and Queneau's algorithmic story Un conte a votre façon, with its multicursal structure. Jeremy Douglass comments on the display of early game-like techniques in this simple tale, which include: "recursion, branch convergence, paratextual branches, retracing, false branches, and more" (Douglass 2007, 142). 


\section{The ALAMO}

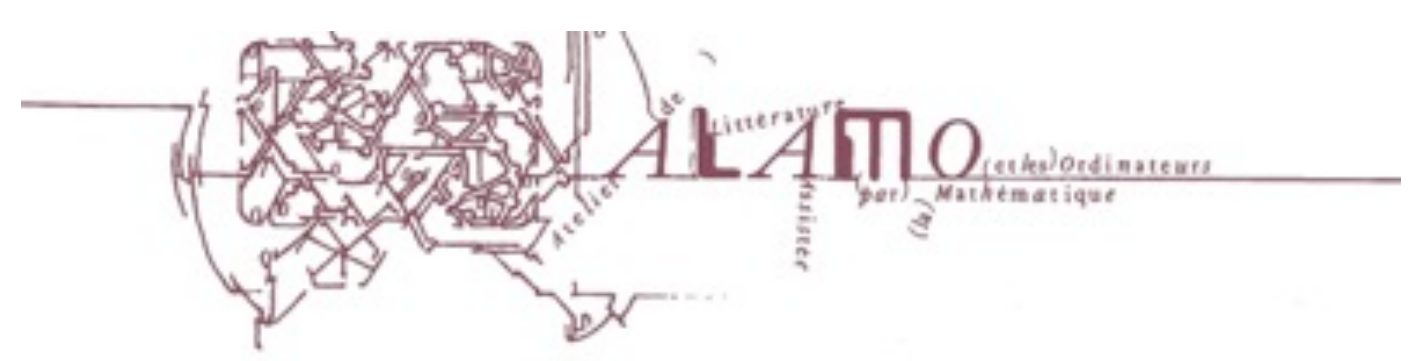

An offshoot of the Oulipo named ALAMO (Atelier de Littérature Assistée par la Mathématique et les Ordinateurs/Workshop for literature assisted by mathematics and computers), was founded by Braffort and Roubaud, and including other oulipians such as Marcel Bénabou and Paul Fournel.

This group continued the combinatorial work, but also added: an "application" level, which allowed word substitutions from a vocabulary (or "ontology" as it would now be termed), such that grammatical sense was maintained; and an "implication" level that deployed logic to generate larger, more complex works. The implication level proved very difficult to achieve, and may be said to be something that is still emerging as a technique, as we shall see later in this paper. The ALAMO eventually produced "litware" programs which progressed essentially by defining rules, then allowing the author to filter the results using the structures of pre-existing works.

Similar groups have developed this approach still further. The group called TEAnO (Telematica, Elettronica, Analisi nell'Opificio), for example, which was formally founded in Florence in 1991 after 8 years of work, has developed computer systems to produce "manufactured aesthetic goods" or, in other words, algorithmic tools for automated artistic creation (Ferrara, Foglia, Maiocchi, 1991). 


\section{To the Nines}

\section{( Networked Infrastructure for $\underline{\text { Nineteenth- Century }}$ \\ Electronic $\underline{\text { Scholarship) }}$}

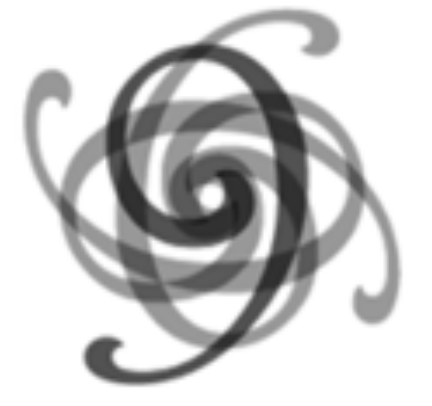

Jerome McGann

October 2005

Such automated techniques do seem to realise at least one aspect of pataphysics. Jerome McGann pointed out that Jarry "treated documents as scenes of precise imaginative possibilities" and that his texts are "sets of instantiated rules and algorithms for generating and controlling themselves and for constructing further sets of transmissional possibilities" (McGann 2001, 2).

Johanna Drucker described the development at University of Virginia of a 'patacritical method, based on puns, which contrasts with the normative effects of standard quantitative methods: "Only a punning method suffices, thus the invention of our term 'patacritical. If norms, means, and averages govern statistics, then sleights, swerves, and deviation have their way in the 'pataphysical game" (Drucker 2009, 26).

"Speculative computing" therefore "struggles for a critical approach that does not presume its object in advance" (ibid. 29). Instead, the aim is to "allow subjectivity to be mapped" by using meteorology metaphors in collective acts of critical activity, including drawing. The 'Patacritical Demon was an elusive and incomplete project which nevertheless still "stands as the energy and sign" of the Speclab.

Their attempt to harness the pataphysical spirit in a critical context produced a collection of tools, such as Collex (an online collections development environment) and Juxta (a textual collection tool), which were eventually subsumed into the NINES (Networked Infrastructure for Nineteenth Century Electronic Scholarship) project. 


\section{merove}

More recently, the digital humanities have increasingly moved towards the web, as offline formats such as CDROM have fallen into disuse and web technologies have improved in leaps and bounds.

Through a pataphysical lens, we may view the web as the Squitty Sea. Every day we must sail across a vast ocean of merdre. The unreliability of its arbitrary encounters requires what Howard Rheingold calls "crap detection" of a high order (Rheingold 2012, 77). This is particularly necessary in an academic context, where provenance is so important.

But this pataphysical navigation does also seem capable of inspiring creativity. Perhaps it is the act of searching that offers that possibility: dying to find meaning in the sea of stuff. Artistic techniques such as data sonification or visualisation evoke this spirit.

However, there is a problem. The way the web is being engineered all too often works against creativity. It is becoming increasingly predictable, repetitive, unoriginal, and unsurprising. While it does provide a useful platform for creative work, it offers less and less in the way of creative technologies.

What is needed is a novel set of rules that will make an exceptional tool for creativity, not just because (as the cliché runs) "it is the exception that proves the rule", but rather because, as Christian Bök (Bök 1996, 39) observed: "[...] the rule itself is the exception in a pataphysical science that rules out the rule." 


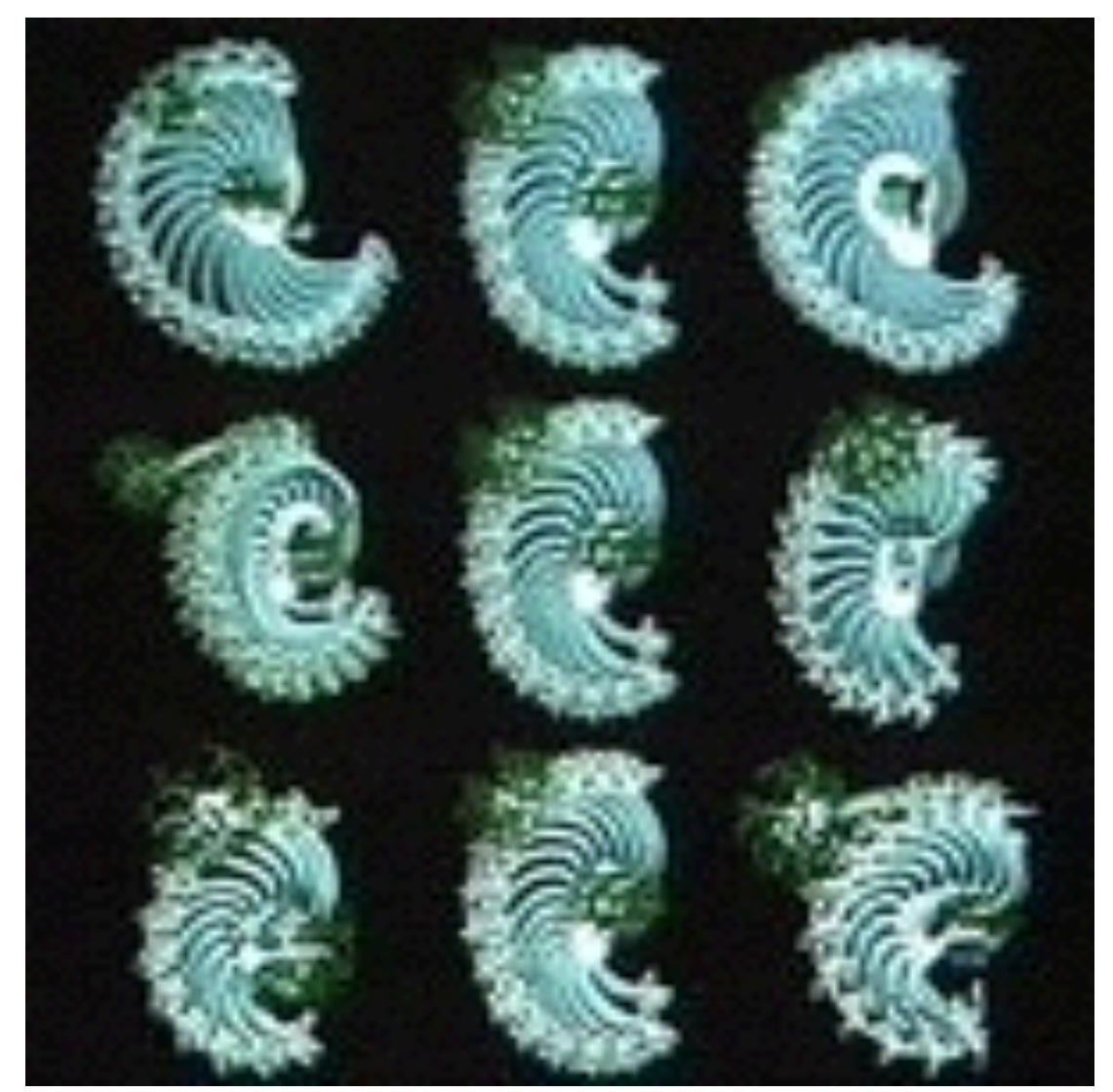

A complete account of creativity is of course beyond the scope of this paper. It may be tentatively defined as: the ability to use original ideas to create something new and surprising of value.

Margaret Boden defines two types of creativity that she calls P-creativity (short for psychological creativity), which is the personal kind of creativity that is novel in respect to the individual mind, and $\mathrm{H}$-creativity (short for historical creativity), which is fundamentally novel in respect to the whole of human history. (Boden 2003, 82)

Using Boden's definition we can call an idea "new" if it is new to the individual who came up with it, making the idea P-creative. We can say that a creative idea can be seen from two perspectives: the subjective (P-creative) and the objective (H-creative) view. Constraints support creativity, and are even essential for it to happen, because "constraints map out a territory of structural possibilities which can then be explored, and perhaps transformed to give another one" (ibid. 83).

Boden defines three sub-types of creativity.

- Combinational creativity: making unfamiliar combinations of familiar ideas (bisasociation, juxtapositioning of unrelated ideas, puns, etc.). We may map this onto the antinomial and syzygystic operations of pataphysics.

- Exploratory creativity: exploration of conceptual spaces (noticing new things in old places). Again, syzygies and anomalies seem relevant here. 


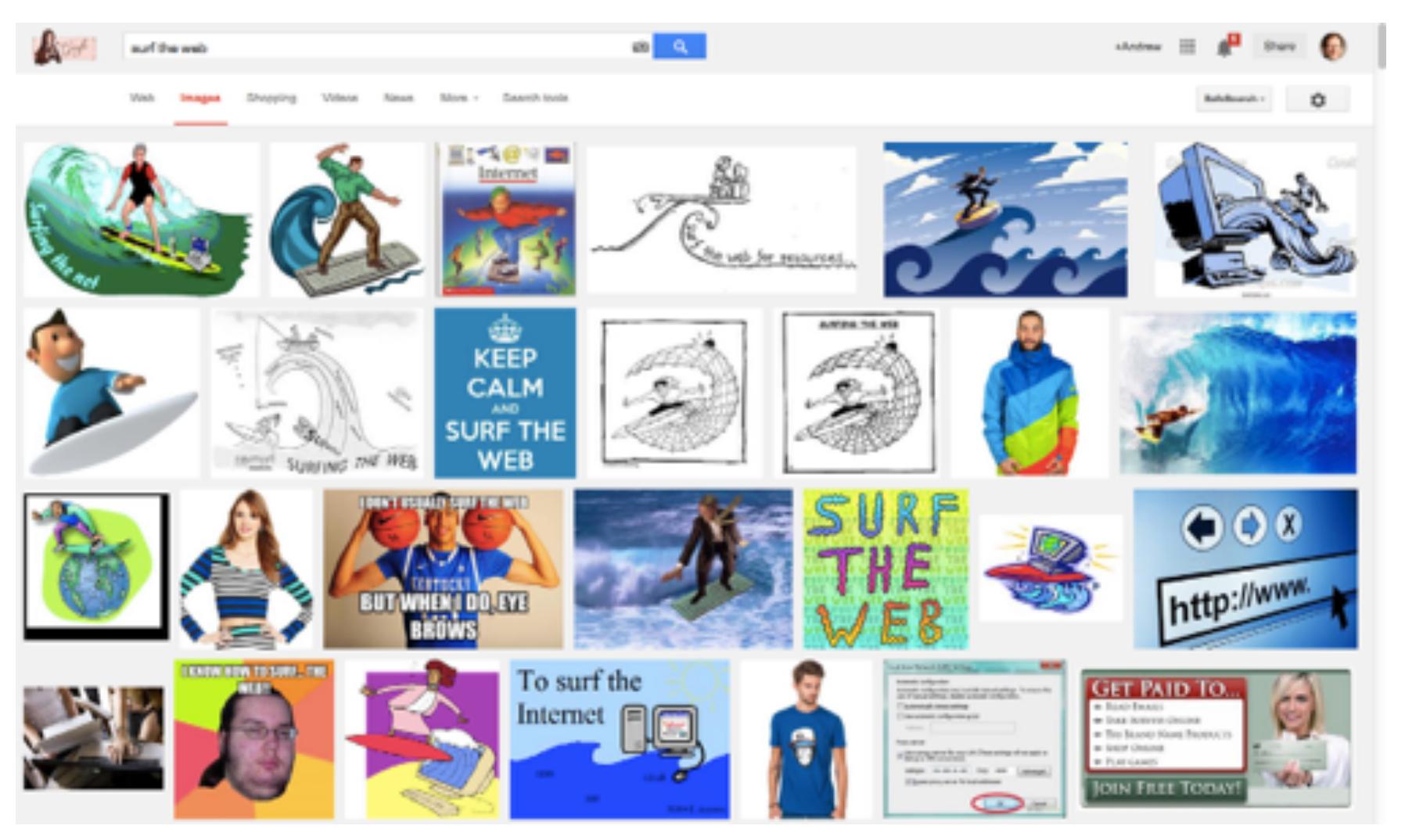

21

The original conception of the World Wide Web seemed designed to encourage creativity. Coming to the Web was a voyage of discovery, aimed at tracking how things connected, rather than just what they were about. Users who downloaded the early browser-prototypes would go to some starting place, such as Cern's TheProject.html, and start exploring. Much of the joy was in finding new and different things one did not know existed. To provide a metaphor for this interaction, in an article in 1992 Jean Armour Polly introduced the term 'surfing':

I weighed many possible metaphors. I wanted something that expressed the fun I had using the internet, as well as hit on the skill, and yes, endurance necessary to use it well. I also needed something that would evoke a sense of randomness, chaos, and even danger. (Polly, 1992) 


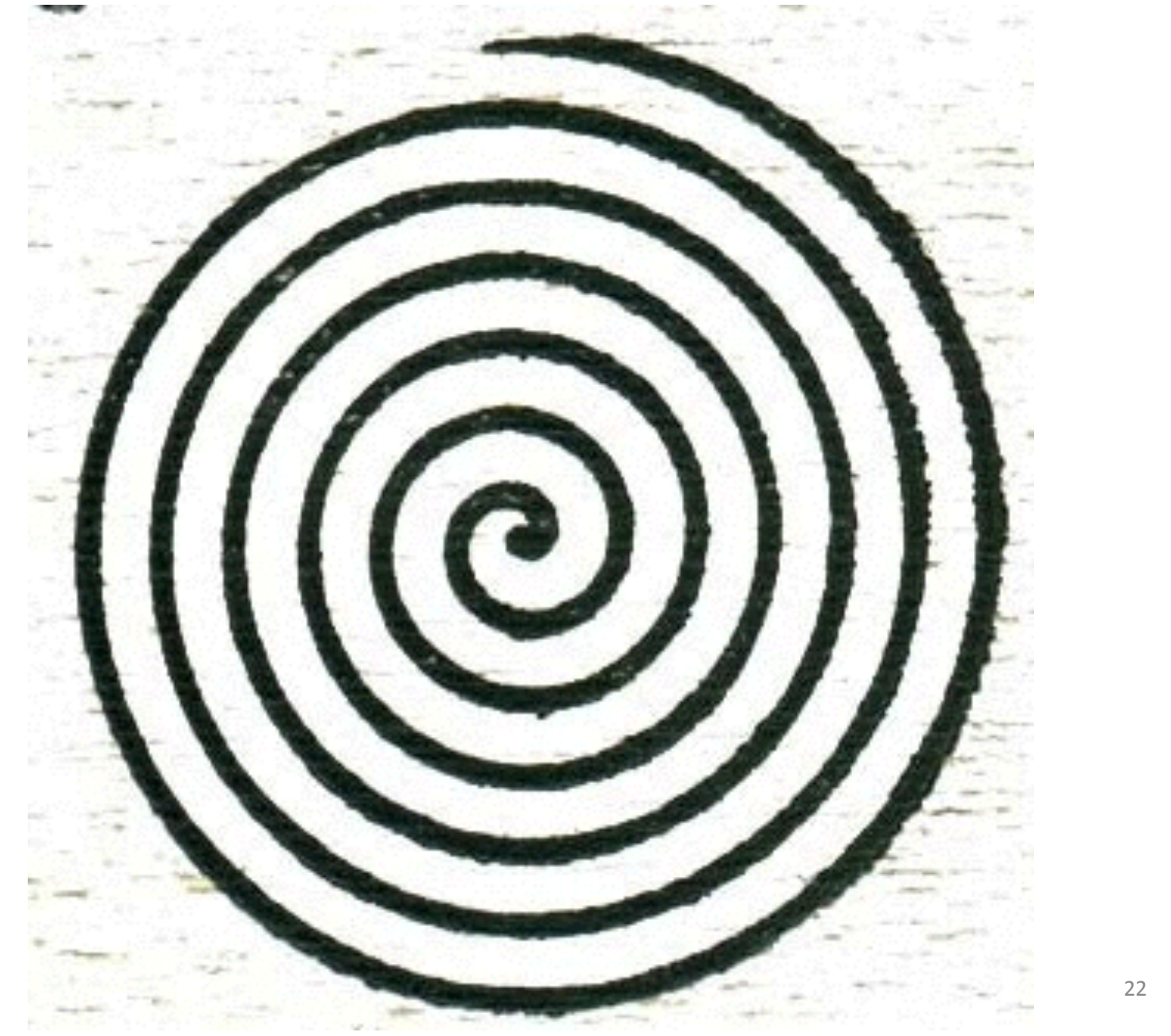

Nowadays, as the web has begun to develop an intelligence of its own, a greater level of machine comprehension, a richer and more targeted user experience, is promised. The Semantic Web is already established in fields such as biochemistry and genetics, whose systems readily suit the formation of its vocabularies, or "ontologies". In the arts and humanities, the picture is more patchy, but some fields are developing semantic toolsets.

The problem with the way this technology is evolving is that it is failing to reconcile itself with the contradictions and exceptions which constitute pataphysics. In other words, as Jim Hendler remarks, it has fallen into the hands of "the forces of neatness". The objective of the semantic web is apparently ever greater precision. But, as we have seen, it is ironically through precision that pataphysical liberty may be found.

Pataphysicians may take courage from the idea that this technology lends itself to creative use and abuse. A pataphysical ontology is one in which the laws governing exceptions and contradictions are expressed through the syllogistic platform for transcendent eccentricity provided by RDF triples. Equivalences may be deployed that contradict expectations. Queries may return results that stand at a clinamen swerve away from the predictable path. The time is ripe for a pataphysical project that builds upon metadata. Hendler and I call this patadata, which is to metadata as metadata is to data. 


\section{RDF Triples}

$<$ object. . $><$ relation. . $><$ value... $>$

For example, a blue balloon would be

$<$ balloon.. $><$ hasColour.. $><$ blue... $>$

To put flesh on the bones of this idea, let us remember that the majority of semantic search systems use Resource Description Framework (RDF) triples as a way of storing data, based on semantic web ontologies. In RDF, each entry to the data store has the following attributes: <object. . $><$ relation. . $><$ value... $>$. For example, a blue balloon would be $<$ balloon.. $><$ hasColour.. $><$ blue... $>$. The $<$ relation $>$ part of the RDF triple provides us with opportunity to insert pataphysical terms. 


\section{Description Logics}

- assertional (ABox) axioms,

Mother(julia) asserts that Julia is a mother

parentOf(julia,john) states that Julia is a parent of John;

- terminological (TBox) axioms,

Mother is subsumed by the concept Parent,

Person and Human are equivalent concepts;

- relational (RBox) axioms,

parentOf includes ancestorOf, etc.

Engines use various forms of computer logic to search data stored in this format: inference logic; fuzzy set theory; and so on. I would like to propose some pataphysical additions to description logic that will transform the capabilities of these engines.

"Description logics are a family of knowledge representation languages that are widely used in ontological modeling" (Krötzsch, Simančík, Horroks 2013, 1). A typical Description Logic ontology consists of a set of statements, or axioms, which only ever represent partial knowledge of a state of affairs. The axioms are divided into:

- $\quad$ assertional (ABox) axioms, such as: Mother(julia) which asserts that Julia is a mother; or parentOf(julia,john) which states that Julia is a parent of John;

- terminological (TBox) axioms, such as: Mother is subsumed by the concept Parent; or Person and Human are equivalent concepts;

- $\quad$ relational (RBox) axioms, which specify roles, such as: parentOf includes ancestorOf; and more complex relationships. 


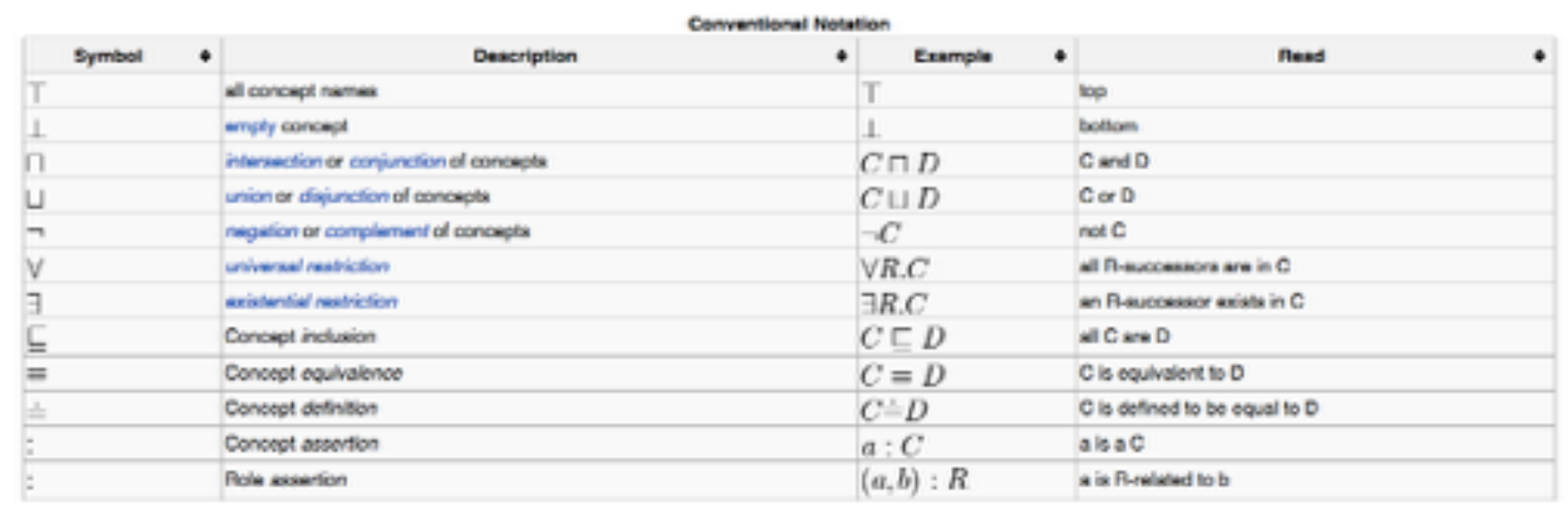

These axiom types are expressed by a new set of symbols, which may be illustrated by the chart shown, in which $C$ and $D$ are concepts, a and $b$ are individuals, and $\mathrm{R}$ is a role. 


\section{Pataphysical DL symbols}

$\because$ Alignment $\quad C \therefore D \quad C$ is aligned with D
$=\quad$ Devposition $\quad C-I-D \quad C$ is opposed to D

Description logic allows one to build new concepts and roles, so offers some potential for creativity. I therefore propose adding three new symbols to this collection, which may be used in pataphysical description logic, as follows:

1. The clinamen $=$ swerve of concepts

2. The syzygy = alignment of concepts

3. The antinomy = mutually antagonistic concepts that nevertheless coexist.

The introduction of a pataphysical mathematics at such a fundamental level within the logics that inform the semantic web will surely have a galvanising effect upon the engineering of this new technology. The symbols, and perhaps others such as the gidouille, may be added to extensible programming languages, to immediate pataphysical effect. 


\section{Syzygy Surfer}

Syzygy Surfer is not random!

unlike...

The Useless Web http://www.theuselessweb.com/

Random Website http://www.randomwebsite.com/

Randominio http://www.randominio.com/

Work has already started on these ideas. In 2010, Hendler and I outlined a new kind of search engine, which we called the Syzygy Surfer. It is an engine that does not take you where you want to go, but somewhere you did not expect to go, but are glad you went there when you arrive. Its linkings are made at a patadata level.

The user experience of the Syzygy Surfer is far from random. Engines such as The Useless Web http://www.theuselessweb.com/, Random Website http:// www.randomwebsite.com/ and Randominio http://www.randominio.com/ already perform this function admirably. 


\title{
Borges' Chinese Encyclopedia: Definitions of 'animals'
}

\author{
those that belong to the Emperor, \\ embalmed ones, \\ those that are trained, \\ suckling pigs, \\ mermaids, \\ fabulous ones, \\ stray dogs, \\ those included in the present classification, \\ those that tremble as if they were mad, \\ innumerable ones, \\ those drawn with a very fine camelhair brush, \\ others, \\ those that have just broken a flower vase, \\ those that from a long way off look like flies.
}

Rather, the experience echoes the kind of surprising yet charming encounter that is captured in Jorge-Luis Borges' celebrated description of 'a certain Chinese Encyclopedia', the Celestial Emporium of Benevolent Knowledge, in 'The Analytical Language of John Wilkins'. The entry on 'animals', it will be recalled, divides them thus.

This displays a sense of poetic unity and quirky verisimilitude that attracted the attention of Michel Foucault, amongst others, who used it as the opening premise of his 1966 book Les Mots et les choses: une archéologie des sciences humaines (On the Order of Things: An Archaeology of the Human Sciences). Making a categorisation like this cannot be done via statistical regularity nor can it be achieved using traditional categorical knowledge. Rather, it seems that we need something that can permute knowledge about the regularities in the world, but in a not-totally-random fashion - we must exploit connections among concepts in a new way so as to generate relations that seem interesting, but unusual.

The first step is for the ontologist, or the pataphysician in this case, is to decide how things will be grouped. The ontologist is not constrained to use simple categories and relations, in fact one could use, for example, the fourteen classes from Borges as the categories in an ontology and define a sorting of objects into these. More challenging, however, would be defining the sorts of relations that would cause us to decide which objects might go into these classes. 


\begin{tabular}{|c|c|}
\hline Class & Relations \\
\hline Those that belong to the Emperor & culturally specific, royal, possessive \\
\hline embalmed ones & past, preserved \\
\hline those that are trained & made uniform, commonalities \\
\hline suckling pigs & young, edible, noisy \\
\hline mermaids & seductive, semi-human \\
\hline fabulous ones & mythical, imaginary \\
\hline stray dogs & $\begin{array}{l}\text { outside known networks, rough and } \\
\text { ready }\end{array}$ \\
\hline $\begin{array}{l}\text { those included in the prosent } \\
\text { classification }\end{array}$ & organized, self-similar \\
\hline those that tremble as if they were mad & uncontrolled, incoherent \\
\hline innumerable ones & general, multiple \\
\hline $\begin{array}{l}\text { those drawn with a very fine camelhair } \\
\text { brush }\end{array}$ & $\begin{array}{l}\text { culturally specific, aesthetccally } \\
\text { distinct }\end{array}$ \\
\hline others & nen-categorical, unspecifiable \\
\hline $\begin{array}{l}\text { those that have just broken a flower } \\
\text { vase }\end{array}$ & present, errant, mischievous \\
\hline $\begin{array}{l}\text { those that from a long way off look like } \\
\text { flies }\end{array}$ & swarming around a particular topic \\
\hline
\end{tabular}

Here we expand Borges' Chinese encyclopaedia by looking at some examples of the evocative relations that the categories depend on. Stating that these relationships exist is non-problematic, but defining the features of them unambiguously would be arbitrarily hard. 


\section{Panalogy}

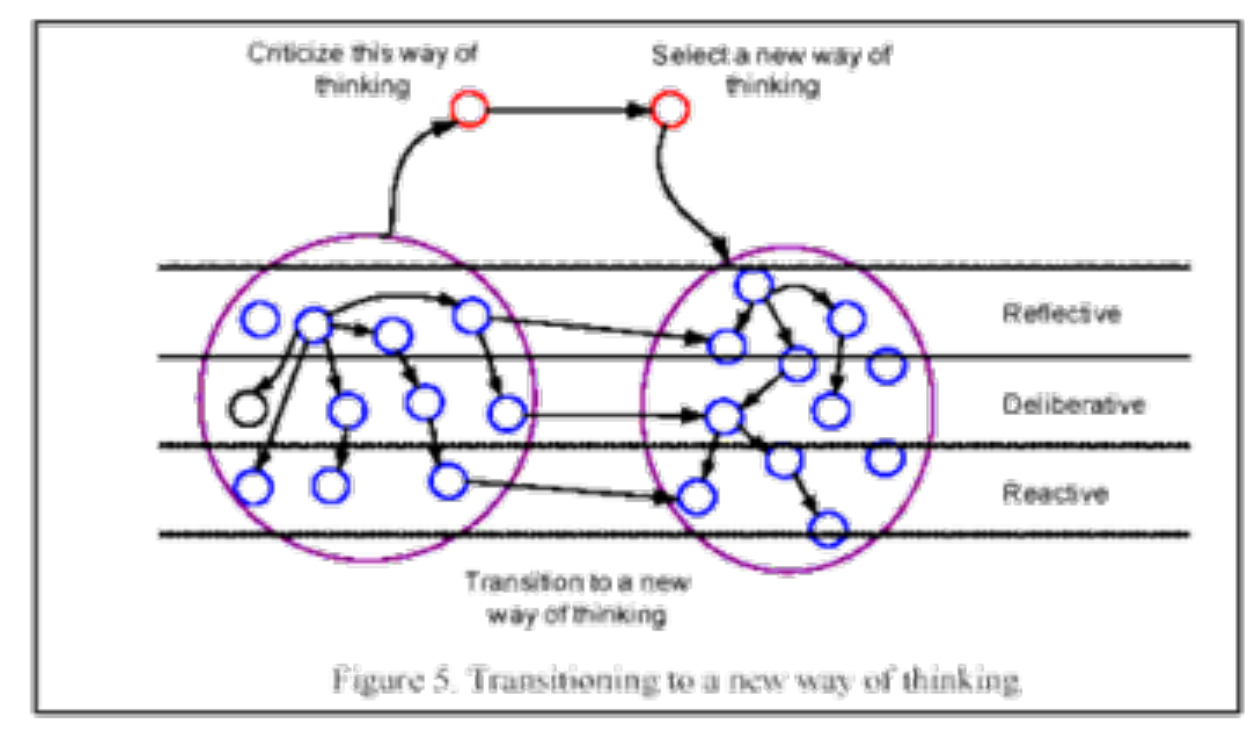

The syzygy surfer works by taking input from a user and generating a panalogical patadata structure for each entry. Pataphysical concepts such as syzygy, clinamen, and anomaly, are then applied to vary the user's terms into a "creatively related" search.

"Panalogy", or parallel analogy, is a concept developed by Push Singh and Marvin Minsky. The idea behind panalogy is that our understanding of any object or action cannot easily be explained in any single conceptualisation. As Minsky explained it in his book The Emotion Machine :

"The Panalogy Principle: If you 'understand' something in only one way then you scarcely understand it at all-because when something goes wrong, you'll have no place to go. But if you represent something in several ways, then when one of them fails you can switch to another. That way, you can turn things around in your mind to see them from different points of view - until you find one that works well for you now. And that's one of the things that 'thinking" means!" (Minsky, 2006)

In combining the ambiguity of natural language with the precision of semantic web ontologies, creative panalogies will deliver patadata. Thus, a panalogy may become a way to conceptualise a computational model for introducing ambiguity, because the same object may be formally ontologised in a number of ways. 


\section{Traditional search engine architecture}

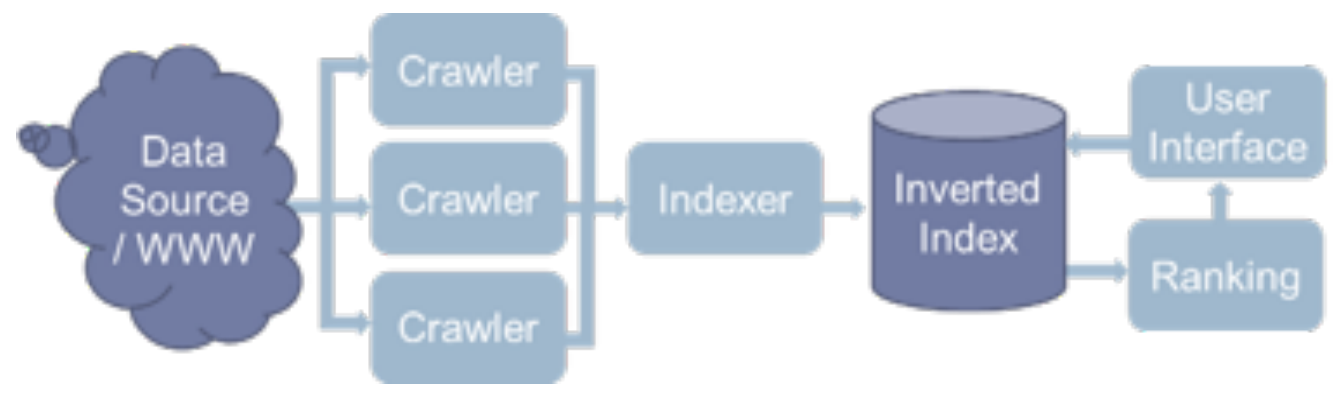

1. Problem identification $=$ information need (IN),

2. Need articulation $=\mathrm{IN}$ in natural language terms,

3. Query formulation = translate IN into query terms, and

4. Results evaluation = compare against IN.

If we compare a pataphysical search with traditional search, some key differences emerge. Most big search engines like Google, Baidu or Bing focus on usefulness and relevance of their results. Other search engines like YossarianLives (YossarianLives 2012), currently in alpha release, concentrate on purely abstract concepts like metaphors for their search algorithms.

A typical traditional search is shown. Here, a user is looking for some information, so she or he types a search term or a question into the text box of a search engine. The system analyses this query and retrieves any matches from the index, which is kept up to date by a web crawler. A ranking algorithm then decides in what order to return the matching results and displays them for the user. In reality of course this process involves many more steps and level of detail, but it provides a sufficient enough overview.

From the users' point of view the search process can be broken down into four activities (Sutcliffe and Ennis 1998, 321), that are reminiscent of classic problem solving techniques (Polya 1957).

Searching can be thought of in two ways: information lookup (searching) and exploratory search (browsing) (Marchionini 2006, 43). A situation where an information need cannot easily be articulated or in fact is not existent (the user is not looking for anything specific) can be considered a typical case of exploratory search and describes the kind of search that is most suited to our proposed tool. 


\section{Pataphysical search engine}

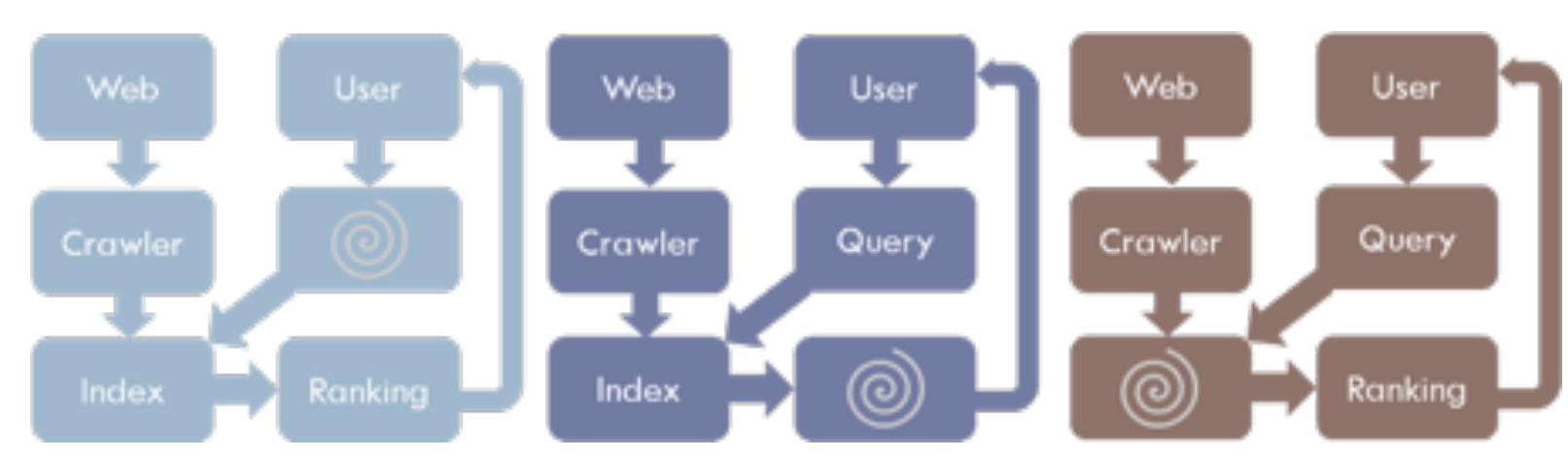

A pataphysical search still contains many of the traditional components, but it has slightly different inner workings and target a different audience of users. The constraints for our conceptual space are the pataphysical rules that we want to apply to our data. We use those rules to explore, combine and transform our space; giving us the flexibility and freedom we need to find interesting results. We can deploy pataphysical interventions, as shown. 


\title{
Possible implementation of Pataphysical
}

search

\author{
Automobile - Wikipedia, the free encyclopedia
en wikipedia org/wiki/Automobile \\ An automobile, autocar, motor car or car is a wheeled motor vehicle used for \\ transporting passengers, which also carries its own engine or motor.
}

We may even envisage the embedding of a pataphysical search option, as in this green candle alternative to a google search. 


\section{Examples}

Query = "Tree"

- Patadata = [Tree(equivalent), Car(opposite), Paper(antinomy), Narwhal(anomaly), Book(syzygy), Venus Fly Trap(clinamen)]

\section{Query = "Sun God Ra"}

- Patadata = [Sun God Ra(equivalent), Slave(opposite), Holiday(antinomy), Blue Balloon(anomaly), Pyramid(syzygy), Sphinx(clinamen)]

This search engine deploys pataphysical query methods as in these examples:

A query on the word "Tree" gives us the following patadata:

[Tree(equivalent), Car(opposite), Paper(antinomy), Narwhal(anomaly), Book(syzygy), Venus Fly Trap(clinamen)]

A similar query on "Sun God Ra" returns the patadata:

[Sun God Ra(equivalent), Slave(opposite), Holiday(antinomy), Blue Balloon(anomaly), Pyramid(syzygy), Sphinx(clinamen)] 
Pataphysical Search!

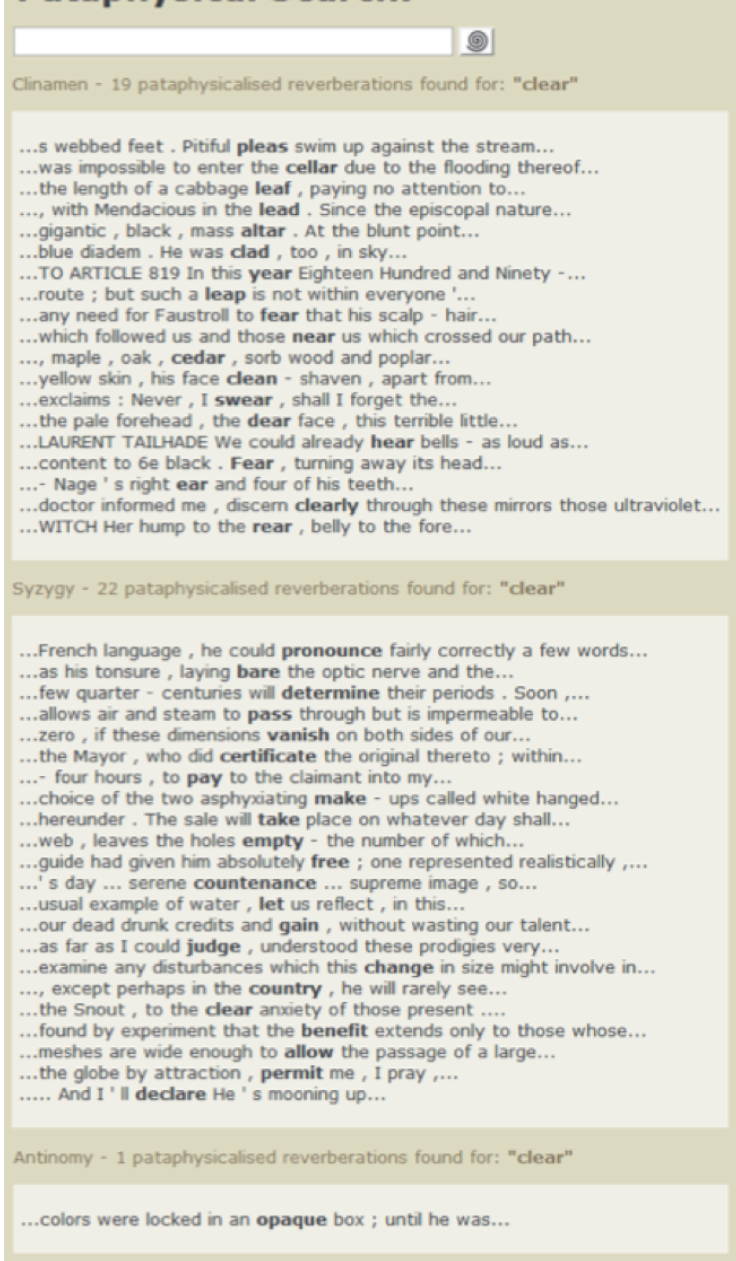

http://pata.fania.eu

The project team comprises myself, Hendler, Professor Hongji Yang and PhD students Lee Scott and Fania Raczinski. Fania has constructed a prototype which searches only on Faustroll. It may be viewed at http://pata.fania.eu Here it shows the results of a search on the word 'clear'. 


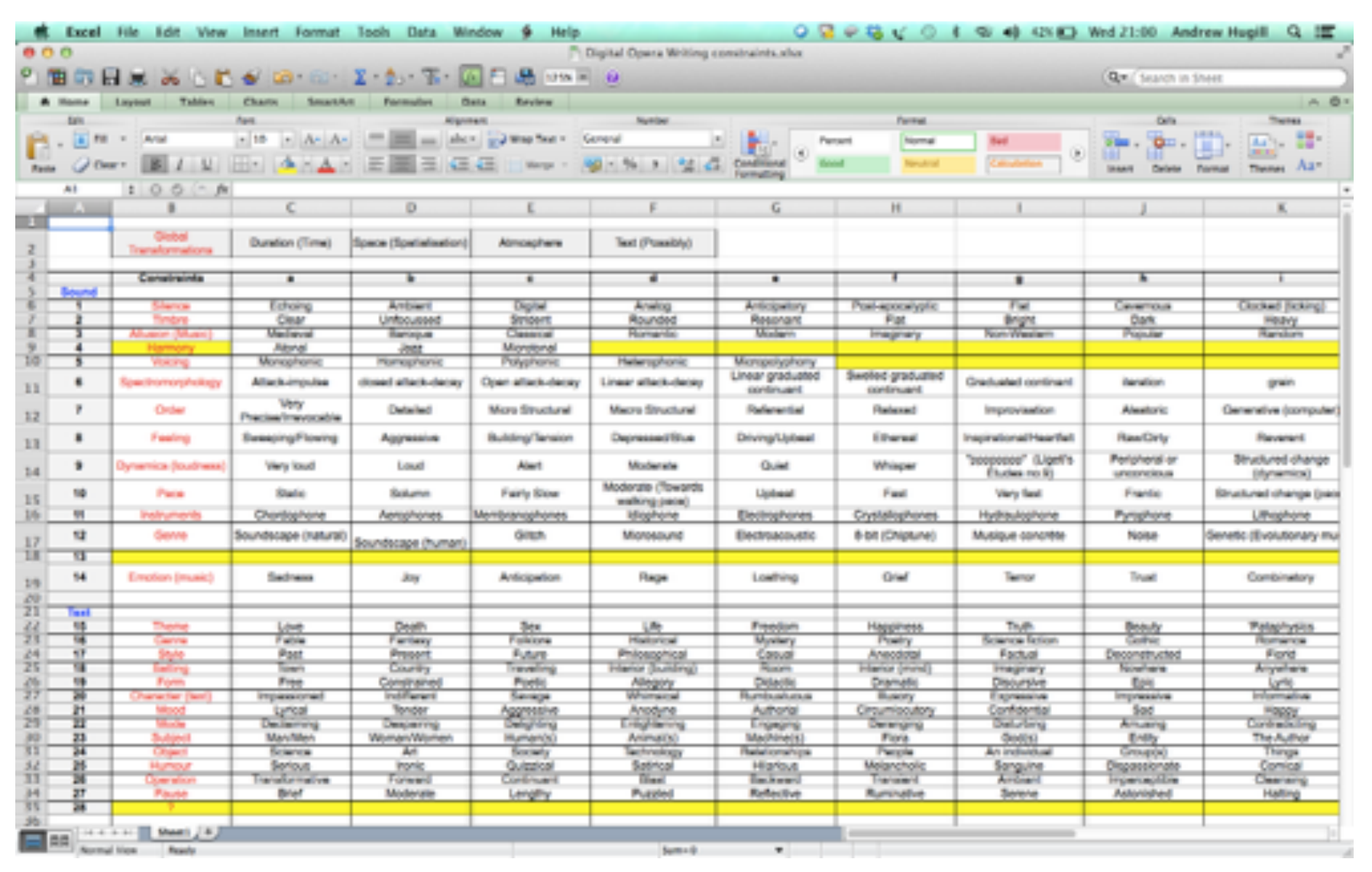

http://theimaginaryvoyage.com

For a more artistic application of the Syzygy Surfer, I would refer you to the online opera The Imaginary Voyage, parts of which were shown at the Slought Foundation the other night. It may also be viewed at www.theimaginaryvoyage.com

This work deploys the Syzygy Surfer in a variety of ways for its operatic 'islands'. In the Isle of Cack, for example, one perceives that there is a relationship between what is seen and what is heard, but these relationships are elusive, startling, and ever-changing. In the Amorphous Isle we use the prototype to generate the libretto which then is interpreted by the engine to deliver sounds and vocal settings that are expressively linked at the patadata level. The matrix shown here gives some idea of the scale of the database used in this work. 


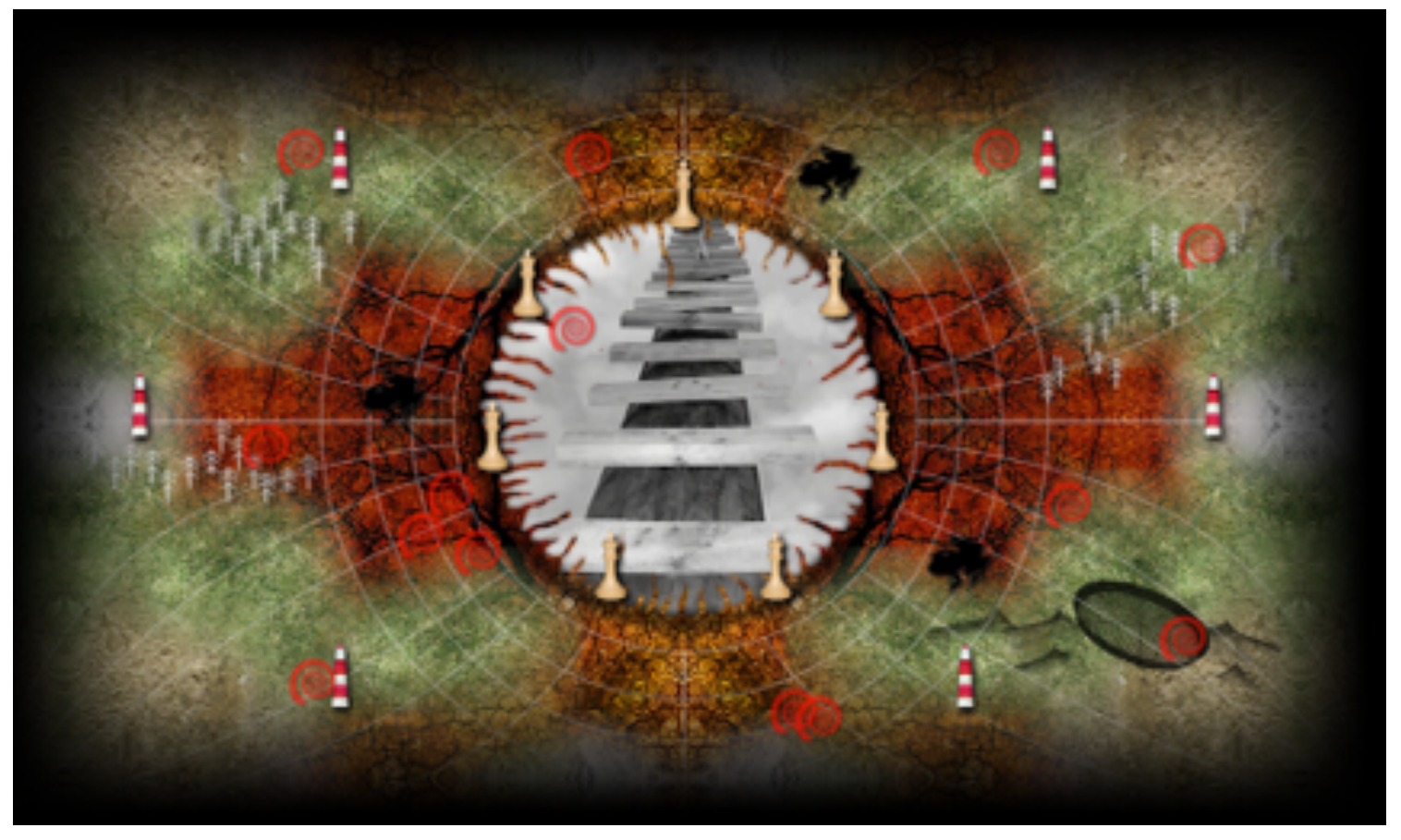

I'll conclude with this quincuncial projection of the Amorphous Isle.

The kind of speculations I have outlined in this talk lie at the heart of what we are calling 'Creative Computing': a meta-technology designed to coalesce knowledge in computing and other disciplines. Through this we aim to achieve creativity in computation. It is this creative spark which I think gives pataphysics its continued relevance and vivacity. 